\title{
An Empirical Study on the Relationship between Atmospheric Environmental Quality and Economic Growth in Shaanxi Province
}

\author{
Rong $\mathrm{Guo}^{1 *}$ \\ ${ }^{1}$ Xi' an Jiaotong University City College, Management department, Shaanxi province, 710018, China
}

\begin{abstract}
According to the panel data of Shaanxi province from 2005 to 2018, the simultaneous equations were constructed through cubic polynomials to study the relationship between the atmospheric environment and economic growth in Shaanxi. The results show that the relationship between air pollution and GDP per capita in Shaanxi province presents an inverted n-shaped curve, which indicates that the economic growth in Shaanxi province causes the fluctuation of air quality, and reflects the relationship that the air pollution in Shaanxi improves first, then worsens and finally improves further with the economic growth. At the same time, the research results show that adjusting the industrial structure, increasing investment in environmental management, reducing the emission of atmospheric pollutants, and reducing energy consumption can promote the sustainable development of the Shaanxi economy and improve the quality of the atmospheric environment.
\end{abstract}

\section{The introduction}

China implements the strategy of developing the western region to promote the coordinated development of the regions in 2000. General secretary Xi Jinping has issued the "One Belt And One Road" initiative in 2013. Shaanxi plays the role of bridgehead in western development and is also the core area of "One Belt And One Road", which is the important fulcrum of the Eurasian land bridge. At the same time, High and frequent air pollution is a threat to people's health, Stable and rapid economic development affects people's life. How to find a balance between atmospheric environment and economy has become the focus of the government and many scholars. Because of this, based on the time-series data from 2005 to 2018 and panel data from 10 cities and 1 demonstration area in Shaanxi, this paper uses empirical analysis to study the relationship between economic growth and the atmospheric environment in Shaanxi, to provide a decision-making basis for sustainable economic development and atmospheric environment improvement.

\section{Index selection and model setting}

The relationship between economic development and environmental quality began at the end of the 20th century. The representative scholars were Grossman and Krueger (1991), who concluded that there was an "inverted U-shaped" curve between them through the analysis of economic and environmental data of the North American Free Trade Area. David I. Stern (1994),
Shaw (2001), and other scholars supported the existence of an "inverted U-shaped" curve between economy and environment through research. Shafik (1994), Hannes (2001), and other scholars concluded through empirical research that there are other curve characteristics between economy and environment, such as "positive Ushaped", "positive N-shaped" and "inverted N-shaped".

Domestic scholars began to study the relationship between economic development and environmental quality at the beginning of the 21 st century. For example, Yuping $\mathrm{Wu}$ (2002) conducted an empirical study to simulate the curve relationship between environment and economy by collecting data from Beijing from 1985 to 1999. According to the research of domestic and foreign scholars, the indexes selected in this paper are as follows:

\subsection{Index selection}

Since environmental data have been published since 2005 , the original data collected in this paper are from The Statistical Yearbook of Shaanxi province, The Statistical Yearbook of Shaanxi Province, and the Statistical Yearbook of Xi'an from 2005 to 2018. The indicators are obtained through collation and corresponding calculation.

Also, since the emission indicators of Xi Xian New Area were not counted until 2017, to maintain consistency, this paper selected 10 cities and 1 demonstration area that were continuously counted in the statistical yearbook of Shaanxi province. The indicators selected are as follows:

- Economic growth, measured by Per capita GDP.

\footnotetext{
$\overline{\text { * Corresponding author: } 121415940 @ q q . c o m}$
} 
- Atmospheric environment quality $(Q)$. According to the statistical indicators of the statistical yearbook, three indicators were adopted in this paper, namely, per capita sulfur dioxide emissions $\left(\mathrm{SO}_{2}\right.$, ton / 10,000 people $)$, per capita NOX emissions (NO, ton / 10,000 people), and per capita carbon emission (S, ton / 10,000 people).

- Air pollution regulation $(F)$ is represented by three indicators, namely, the number of exhaust gas treatment facilities per capita $\left(F_{a}\right.$, set / 10,000 people $)$, the treatment capacity of exhaust gas treatment facilities per capita $\left(F_{b}\right.$, cubic meter/hour/person) and the operating cost of exhaust gas treatment facilities per capita $\left(F_{c}\right.$, yuan/person).

- The industrial structure is measured by two indicators, namely, the per capita gross industrial output value (IOV, yuan/person) and the per capita energy consumption of industrial enterprises above the scale $(C$, ton standard coal/person).

- Control variables, other indicators that affect economic development, and atmospheric pollutant emissions. Population density ( $P$, people/ square $\mathrm{km})$ is obtained by dividing the number of permanent residents in each city by its land area at the end of each year. Annual precipitation $(T P, m l)$ is represented by the annual precipitation of each city.

\subsection{Model building}

This paper constructs simultaneous equations based on cubic polynomials to investigate the relationship between atmospheric environment and economic growth in Shaanxi province.

The air quality is represented by three indicators, namely, per capita sulfur dioxide emissions, per capita NOX emissions, and per capita carbon emission.

$L n G D P_{i t}=\alpha_{0}+\alpha 1 \ln Q_{i t}+\alpha_{2} \ln I O V_{i t}+\varepsilon_{i t}$

$L n Q_{i t}=\beta_{0}+\beta_{l} \ln G D P_{i t}++\beta_{2}\left(\ln G D P_{i t}\right)^{2}+\beta_{3}\left(\ln G D P_{i t}\right)^{3}$

$+\beta_{4} \ln F_{i t}+\beta_{5} \ln C_{i t}+\beta_{6} \ln P_{i t}+\beta_{7} \ln T P+\delta_{i}$

Equation (1) is the output equation, indicating that in the form of Cobb-Douglas production function, GDP per capita is atmospheric environment quality $(Q)$ and industrial output per capita above the scale ( $\mathrm{IOV})$.

Equation (2) is the environmental equation, where air pollution $(Q)$ contains three proxy variables, namely, per capita carbon emission $(S)$, per capita sulfur dioxide emission $\left(\mathrm{SO}_{2}\right)$ and per capita nitrogen oxide emission $(N O)$.

By the regression coefficient of the above equation $\beta$, the relationship curve between the atmospheric environment and economic growth can be judged. The curve may present the following situations:

Table 1. Relationship between parameter symbols and curve morphology.

\begin{tabular}{|c|c|}
\hline $\begin{array}{c}\text { Coefficient } \\
\text { values }\end{array}$ & $\begin{array}{c}\text { The relationship } \\
\text { between } \\
\text { economic growth } \\
\text { and atmospheric } \\
\text { environment }\end{array}$ \\
\hline
\end{tabular}

\begin{tabular}{|c|c|}
\hline$\beta_{1}=\beta_{2}=\beta_{3}=0$ & No correlation \\
\hline$\beta_{1}>0, \beta_{2}=\beta_{3}=0$ & $\begin{array}{c}\text { Linear relation: } \\
\text { Monotone } \\
\text { increasing }\end{array}$ \\
\hline$\beta_{1}<0, \beta_{2}=\beta_{3}=0$ & $\begin{array}{c}\text { Linear relation: } \\
\text { Monotone } \\
\text { decreasing }\end{array}$ \\
\hline$\beta_{1}>0, \beta_{2}<0, \beta_{3}=0$ & $\begin{array}{c}\text { Inverted U-shaped } \\
\text { curve }\end{array}$ \\
\hline$\beta_{1}<0, \beta_{2}>0, \beta_{3}=0$ & U curve \\
\hline$\beta_{1}>0, \beta_{2}<0, \beta_{3}>0$ & N curve \\
\hline$\beta_{1}<0, \beta_{2}>0, \beta_{3}<0$ & $\begin{array}{c}\text { Inverted N-shaped } \\
\text { curve }\end{array}$ \\
\hline
\end{tabular}

From 2005 to 2010, the exhaust emission index of Shaanxi Statistical Yearbook did not count the per capita NOX emission index. In 2018, the emission targets of Xi'an city were counted in $\mathrm{Xi}$ ' a Statistical Yearbook, but none of the other cities were counted. Therefore, the original data of this paper include 10 cities and 1 district in Shaanxi province, with a total of $\mathrm{N}=143$ observed values. The non-equilibrium panel is used for empirical study.

The main statistical values of each variable are shown in Table 2 .

Table 2. Main statistics of variables.

\begin{tabular}{|c|c|c|c|c|}
\hline $\begin{array}{c}\text { Variable } \\
\text { code }\end{array}$ & The mean & $\begin{array}{c}\text { Standard } \\
\text { error }\end{array}$ & $\begin{array}{c}\text { The } \\
\text { minimum } \\
\text { value }\end{array}$ & $\begin{array}{c}\text { The } \\
\text { maximum }\end{array}$ \\
\hline $\mathrm{GDP}$ & 32928.02 & 21703.49 & 4800 & 112845 \\
\hline $\mathrm{S}$ & 262.35 & 613.34 & 0.96 & 4050.57 \\
\hline $\mathrm{SO}_{2}$ & 164.07 & 184.68 & 3.06 & 974.35 \\
\hline $\mathrm{NO}$ & 137.78 & 168.89 & 3.68 & 655.46 \\
\hline $\mathrm{F}_{\mathrm{a}}$ & 1.44 & 1.40 & 0.29 & 11.26 \\
\hline $\mathrm{F}_{\mathrm{b}}$ & 47.75 & 221.55 & 0.19 & 1707.43 \\
\hline $\mathrm{F}_{\mathrm{c}}$ & 74.55 & 83.39 & 2.17 & 471.21 \\
\hline $\mathrm{IOV}$ & 19168.10 & 13733.70 & 1850.86 & 71038.40 \\
\hline $\mathrm{C}$ & 5.50 & 9.96 & 0.00 & 48.65 \\
\hline $\mathrm{P}$ & 372.55 & 408.06 & 57.25 & 1550.37 \\
\hline $\mathrm{TP}$ & 669.65 & 362.62 & 248.70 & 4318.00 \\
\hline
\end{tabular}

Before the parameter estimation of the antithetical equation model, according to the results in Table 2, the parameter identification problem is first investigated. According to the order conditions of the identifiability, the model set in this paper has many exogenous variables, and both the output equation and the environmental equation belong to over-identification, which is similar to the research results of Ying Feng. Secondly, through the Hausmann test, the model established in this paper has a simultaneous relation, and the simultaneous equation model of the atmospheric environment and economic growth is established.

\section{Empirical results and analysis}

\subsection{The empirical results}

This paper USES 3 SLS STATA15.0 software for data processing, at the same time, due to the atmospheric 
environmental quality by the per capita emissions of sulfur dioxide (SO2), Per capita NOX emissions (NO), Carbon emission per capita (S), three atmospheric pollution indicators to measure, so the regression results show that the results of the three equations, the results are shown in Table 3.

Table 3. Regression results.

\begin{tabular}{|c|c|c|c|c|c|c|}
\hline \multirow{2}{*}{$\begin{array}{c}\begin{array}{c}\text { Equa } \\
\text { tion }\end{array} \\
\text { Result }\end{array}$} & \multicolumn{3}{|c|}{ The output equation } & \multicolumn{3}{|c|}{$\begin{array}{c}\text { Environmental } \\
\text { equation }\end{array}$} \\
\hline & $\operatorname{lnGDP}$ & $\operatorname{lnGDP}$ & $\operatorname{lnGDP}$ & $\ln S$ & $\mathrm{LnSO}^{2}$ & $\operatorname{lnNO}$ \\
\hline \multirow{2}{*}{$\operatorname{lnGDP}$} & & & & -1.467 & -1803.0 & -1.318 \\
\hline & & & & $(-0.32)$ & $(-0.82)$ & $(-0.29)$ \\
\hline \multirow{2}{*}{$\begin{array}{l}(\operatorname{lnGD} \\
\mathrm{P})^{2}\end{array}$} & & & & 0.621 & 179.3 & 0.569 \\
\hline & & & & $(0.71)$ & $(0.83)$ & $(0.69)$ \\
\hline \multirow{2}{*}{$\begin{array}{c}(\operatorname{lnGD} \\
\mathrm{P})^{3}\end{array}$} & & & & -0.0386 & -5.929 & -0.0351 \\
\hline & & & & $(-0.90)$ & $(-0.83)$ & $(-0.90)$ \\
\hline \multirow{2}{*}{$\operatorname{lnS}$} & $0.0050^{* *}$ & & & & & \\
\hline & $(-4.50)$ & & & & & \\
\hline \multirow{2}{*}{$\operatorname{lnSO^{2}}$} & & $-0.0018^{*}$ & & & & \\
\hline & & $(-1.89)$ & & & & \\
\hline \multirow{2}{*}{$\operatorname{lnNO}$} & & & $0.0008^{* *}$ & & & \\
\hline & & & $(-2.38)$ & & & \\
\hline \multirow{2}{*}{$\operatorname{lnF}_{a}$} & & & & 0.104 & 0.886 & $0.817^{* * * *}$ \\
\hline & & & & $(0.24)$ & $(0.83)$ & (3.70) \\
\hline \multirow{2}{*}{$\ln F_{b}$} & & & & -0.0126 & 0.184 & $0.326^{* *}$ \\
\hline & & & & $(-0.06)$ & $(0.62)$ & $(2.42)$ \\
\hline \multirow{2}{*}{$\ln \mathrm{F}_{\mathrm{c}}$} & & & & 0.181 & 0.351 & $0.348^{* *}$ \\
\hline & & & & $(0.62)$ & $(0.98)$ & $(2.42)$ \\
\hline \multirow{2}{*}{$\ln C$} & & & & 0.333 & 0.906 & $\begin{array}{l}0.341^{* *} \\
*\end{array}$ \\
\hline & & & & $(1.32)$ & $(1.58)$ & $(2.94)$ \\
\hline \multirow{2}{*}{$\operatorname{lnIOV}$} & $0.995^{* * *}$ & $0.998^{* * *}$ & $1.002^{* * *}$ & & & \\
\hline & $(630.92)$ & $(754.50)$ & $\begin{array}{l}(1430.6 \\
5)\end{array}$ & & & \\
\hline \multirow{2}{*}{$\ln \mathrm{P}$} & & & & -0.111 & 0.351 & 0.0571 \\
\hline & & & & $(-0.33)$ & $(0.67)$ & $(0.41)$ \\
\hline \multirow{2}{*}{$\operatorname{lnTP}$} & & & & -0.704 & -0.184 & $1.058^{* * * *}$ \\
\hline & & & & $(-0.93)$ & $(-0.16)$ & $(-2.78)$ \\
\hline \multirow{2}{*}{$\begin{array}{c}\text { Consta } \\
\text { nt }\end{array}$} & $0.0982^{* * *}$ & 0.0418 & -0.0032 & $0.0001^{* *}$ & $\begin{array}{l}6026.38 \\
7 \\
\end{array}$ & 0.0001 \\
\hline & (3.30) & (1.60) & $(-0.24)$ & (3.30) & $(0.82)$ & $(0.30)$ \\
\hline $\mathrm{N}$ & 110 & 110 & 60 & 110 & 110 & 60 \\
\hline $\mathrm{R}^{2}$ & 0.9999 & 0.9999 & 0.9999 & 0.2260 & 0.2706 & 0.6938 \\
\hline
\end{tabular}

\subsection{Results analysis}

\subsubsection{The result analysis of output equation}

According to the empirical results of the output equation, firstly, the impact coefficients of the three air pollution indicators in the output equation on per capita GDP were all significantly negative, indicating that the economic development level of Shaanxi would decrease with the increase of the emission of air pollutants.

A $1 \%$ increase in soot emissions will lead to a $0.005 \%$ reduction in per capita production, a $1 \%$ increase in $\mathrm{SO} 2$ emissions will lead to a $0.002 \%$ reduction in per capita production, and a 1\% increase in NO emissions will lead to a $0.0008 \%$ reduction in per capita production, that is, the emission of air pollutants will lead to a reduction in per capita output, affecting per capita income.

Second, the per capita industrial output value of the city above the scale of $99 \%$ confidence, the impact coefficient on per capita output is a significantly positive correlation, indicating that this factor is an important factor affecting per capita output.

\subsubsection{The result analysis of the environmental equation}

First, analyze the result of atmospheric environment quality and economic growth. result analysis. From the perspective of the environmental equation, the calculation results of the estimated coefficients of the three atmospheric environmental pollution indicators selected in this paper show that: $\beta 1$ the results for -1.467 , -1803.0 and -1.318 , namely $\beta 1<0 ; \beta 2$ the results for $0.621,179.3$ and 0.569 , namely $\beta 2>0 ; \beta 3$ the results for $0.0386,-5.929$ and -0.0351 , namely $\beta 3<0$. According to the parameter symbol and curve shape in Table $1, \beta$ $1<0, \quad \beta 2>0, \quad \beta 3<0$, that is, the relationship between atmospheric environmental pollution and per capita GDP shows an "Inverted N-shaped" curve, and economic growth causes fluctuations in atmospheric environmental quality. The inverted $\mathrm{N}$-shaped curve reflects that atmospheric environmental pollution first improves the environmental problems with economic growth, then enters the stage of environmental deterioration, and finally improves the environmental problems. This indicates that Shaanxi's economy grows slowly in the early stage and its consumption of resources and energy is relatively low. In the middle of the statistical fourteen years, rapid economic growth accelerated the consumption of resources and energy, which led to the aggravation of air pollution. In recent years, the government and the public have realized the importance of environmental issues and reduced the emission of air pollution by adjusting the industrial structure and upgrading the industry.

Secondly, the results of air pollution regulation and air environment quality are analyzed. There are three indicators of air pollution regulation, among which the number of exhaust gas treatment sets per capita is positively related to the air environment quality. The capacity of per capita exhaust gas treatment facilities has a positive relationship with per capita sulfur dioxide emissions and per capita nitrogen oxide emissions, and a 
negative relationship with per capita smoke (dust) emissions. The operating cost of exhaust gas facilities per capita is positively related to the three indexes of atmospheric environment quality. The three indicators of air pollution regulation and the three indicators of air environment quality are only positively correlated with per capita NOX emissions, and the coefficient is significantly correlated. The results are similar to the conclusions of Feng Ying et al., Tongsheng $\mathrm{Xu}$, and other scholars. This indicates that air pollution control has not improved environmental pollution. The reasons may be as follows: the facilities invested in air pollution control and the cost are less. According to the environmental governance data of developed countries, to improve the environment, environmental protection funds need to be invested in $1 \%$ to $1.5 \%$ of the gross domestic product. However, in 2017, for example, Weinan city and Lin Yu city, which are heavily polluted, invested $0.66 \%$ and $0.29 \%$ of their GDP respectively. Secondly, the facilities and costs of governance are not stable and continue to increase in accordance with the emission of pollution. Xi'an increased 206 governance facilities in 2017 over the previous year, but the cost decreased by 29.7 percent. The lack of stability of government facilities and costs may be the reason for this empirical result.

Third, the results of the analysis of the industrial structure and atmospheric environment quality. Energy consumption of industrial enterprises above the per capita size is positively correlated with atmospheric environmental quality, and only significantly correlated with nitrogen oxide emissions per capita. This result shows that per capita NOX emissions increase with the increase of energy consumption of industrial enterprises above the size. From 2005 to 2010, the energy consumption of large-scale industrial enterprises continued to increase, and the emission of air pollutants increased, reaching the highest level in 14 years of statistical data. In the three years from 2011 to 2013, the energy consumption of industrial enterprises above a certain size decreased, but the decline was small. From 2013 to 2018, with the upgrading and optimization of industrial structure, the energy consumption of industrial enterprises above a certain scale has been greatly reduced, and the emission of air pollutants has been reduced accordingly.

Fourth, analyze the results of population density, total annual precipitation, and atmospheric environment quality. The indicators of population density on the atmospheric environment are positively correlated with per capita sulfur dioxide emissions and per capita nitrogen oxide emissions, but negatively correlated with per capita smoke (dust) emissions, and are not significant with the empirical results of the three, indicating that the increase of population density does not have an impact on atmospheric environment quality. The total annual precipitation has a negative relationship with the three indicators of atmospheric environment, which is only significant for the per capita NOX emissions. According to the empirical results, precipitation has little influence on the two indicators of SULFUR dioxide emissions and NOX emissions, and precipitation has little effect on their improvement. The reason may be that Shaanxi is a long and narrow region with high terrain from north to south and low terrain in the middle, which is not conducive to the outward diffusion of pollutants. It may even cause the transport of external pollutants to the central region due to wind direction, humidity, and other problems, leading to the accumulation of atmospheric pollutants.

\section{Conclusions}

In this paper, according to the Shaanxi province in 20052018 panel data for empirical research, according to the results of empirical analysis, Shaanxi atmospheric environment quality and the strong correlation between the economic development.

There is an inverted U-shaped curve relationship between atmospheric environmental quality and economic development, which reflects that atmospheric environmental pollution first improves the environmental problems with economic growth, then enters the stage of environmental deterioration, and finally improves the environmental problems.

Second, the emission of air pollutants will lead to a decrease in per capita output, affecting per capita income. An increase of $1 \%$ in the emissions of air pollutants for three indicators would result in a reduction of about $0.003 \%$ in per capita production.

Finally, with the increase in energy consumption per capita of industrial enterprises above a certain size, the emission of air pollution increases.

\section{Acknowledgment}

Fund Items: 2019 Scientific Research Plan of The Education Department of Shaanxi Province, An empirical study on the relationship between atmospheric environmental quality and economic growth in Shaanxi province (Project Approval No. :19JK0493)

\section{References}

1. Hongyun $\mathrm{Bu}$, Jie HUANG, Research on the Harmonious Relationship between Industrial Structure and Environmental Quality in BeijingTianjin-Hebei Region, Commercial Economics Research, 5 (2018).

2. Ying Feng, Xiaoning LI, Guojun QU, Mei Xu, Research on the relationship between water environmental pollution and economic growth in China, Journal of northwest a\&f university (social science edition), 17 (2017).

3. Danlin Yan, Lu GAO, Research on energy Structure Adjustment of Urban Haze Control in China, Commercial Economics Research, 13 (2015).

4. Feng He, Dongdong Ma, Research on the correlation between haze and industrialization development, Soft Science, 29 (2015). 